\title{
Factors That Influence the Performance of Students In Botswana Primary Schools
}

\author{
Maimela, \\ M. Rasetimela Primary School, Bobonong. \\ Monyatsi, P. P. University of Botswana. Gaborone.
}

\begin{abstract}
Ms Maimela is a primary school teacher who has just completed her Bachelor of Education in Primary Education at the University of Botswana. As a primary school teacher she teaches all the subjects on offer. She had a stint as a temporary secondary school teacher before going to college. She has a lot of interest in educational improvement. This article is part of her research project for the B.Ed.Professor P P Monyatsi, University of Botswana, Faculty of Education, Bag 702, Gaborone. 267+3552399; Corresponding Author Professor Pedzani Perci Monyatsi, a Senior Lecturer in Educational Management is currently employed by the University of Botswana as a Teaching Practice Coordinator. He holds a EdD from the University of South Africa. He has served as a secondary school teacher, a school head, a head of department at university level and a lecturer. He has published widely and has seventeen journal articles. His research interests are in teacher education, educational management, administration and leadership.
\end{abstract}

Abstract: Background: The Government of Botswana has since attaining independence from Britain in 1966 demonstrated a lot of interest in the improvement of primary education by adopting two policies; the Education for kagisano of 1977 and the Revised National Policy on Education of 1994 to guide the development of education in the country. Other efforts include partnering with organizations from countries such as the USA and Britain and others to help improve the quality of the primary education. The other major aim for these was to improve the performance of students in the final examinations.

Purpose/Aims:The purpose of the study was to investigate factors that influenced student's performance in Primary School Leaving Examinations. The study is informed by the Conceptual Framework for Exploratory Study on Contributing Factors to Low Academic Achievement by (Nordin, Ahmad, Nayan, Yahya, Abdullah, Rahman, Ismail, and Yunus (2012).

Methodology: A mixed-method design allowed the researcher to triangulate data from the professional literature and a questionnaire comprised of closed and open-ended questions. Out of the two hundred questionnaires distributed, one hundred and twenty seven questionnaires were returned; while only one hundred questionnaires were properly completed and therefore used in the study. Respondents were also interviewed.

Data Analysis: For the closed ended section of the questionnaire, SPSS (Statistical Package for the Social Sciences) software was used. Data from the interviews and open-ended section of the questionnaire was coded, and then emerging patterns and themes were identified and described in order to understand the meanings of these categories from the perspectives of the respondents, with verbatim texts included.

Findings: The findings show thata myriad of factors contribute to the academic performance of the learner in Primary School Leaving Examination (PSLE): parental involvement, medium of instruction, teaching and learning materials, infrastructure, learner - teacher ratio, school libraries, motivation of teachers, qualification of teachers and learners' discipline.

Key words: Botswana, Academic performance; primary education;

\section{INTRODUCTION}

The Government of Botswana has since independence from Britain in 1966 demonstrated a lot of interest in the improvement of primary education by adopting two policies; the Education for kagisano of 1977 and the Revised National Policy on Education of 1994 to guide the development of education in the country. The first National Education Policy adopted in 1977 was based on the four national principles of democracy, development, self-reliance, and unity.It emphasized quantitative developments in education.

The Revised National Policy on Education (RNPE), which was adopted in 1994 (Republic of Botswana, 1994), emphasized the need to improve access to education at the primary level, as well as ensuring that children received quality education which is relevant to them and their communities. One of the goals in primary education isto develop basic skills of literacy, numeracy, and life skills among learners. Some of the strategies described in the policy which aimed at improving the performance of students included: Parental involvement; 
English as a medium of instruction;Introduction of school libraries;Adequate materials;Recruitment of qualified teachers;Motivation of teachers;Teacher-learner ratio; and Infrastructure like classrooms.

Parental involvement is one of the strategies that was recommended by the two policies. The first National Policy on Education of 1977 (Republic of Botswana (1977) recognised the need for parental involvement by stating that "... Education of the young is a joint responsibility of the school, community and parents ... As children grow parents may assist with school readiness by sending them to nursery schools when circumstances permit, (p.56)". It further recommended that, parents should take a general interest in their children's education, visit the school, and hold frequent discussions with teachers as their encouragement can contribute to progress in schools (Republic of Botswana, 1977).

The Revised National Policy on Education of 1994 recommendedthat as much as possible the communities should participate in the development and management of education through consultations with Boards of Governors, Parents Teachers Association (PTA) and other relevant bodies in the community (Republic of Botswana, 1994). Parent Teachers Associations were viewed as providing an effective forum for schools to keep in contact with the communities they served and also to ensure parents took interest and contributed to the education of their children (Republic of Botswana, 1994).

One of the legacies of colonialism is that English has remained an official language and a language of instruction in Botswana. English as a language plays a vital role in the development of learners in Botswana education systemas it is an official language which is used for examinations and at the workplace. Republic of Botswana (1977) states that: "The commission recommends that: English should be taught as a subject from standard 1, with the aim of preparing children for the transition to English as a medium of instruction at standard 5," (p.77). The Revised National Policy on Education of 1994 called for change by also recommending that English should be used as a medium of instruction from standard one by the year 2000. Furthermore it recommendedthat an accelerated programme of in-service training should be undertaken to improve the teaching of English as a subject from standard one with emphasis on oral communication (Republic of Botswana, 1994). The Government of Botswana has over the years struggled to provide adequate materials such as textbooks. However, some remarkable progress has been made as per the Revised National Policy on Education of 1994.The policy recommended that all pupils should have a textbook for each core subject and variation on distribution of resources between schools and regions (Monyaku \& Mmereki, 2012). To ensure the quality of inputs at primary school level in Botswana, the Revised National Policy on Education of 1994 stipulated that the Department of Curriculum Development and Evaluation (DCDE) should form a Textbook Evaluation Committee (TEC). The TEC should comprise teachers' representatives, education officers and representatives of teachers' trade unions. Before any teaching-learning materials and textbooks could beused in schools in Botswana, they have to be evaluated and approved by this committee (Monyaku \& Mmereki, 2012).

The Revised National Policy on Education of 1994 called for more qualitative improvements for the education system. Consequently one of its recommendations required all primary school teachers to have a minimum of Diploma in Primary Education (DPE). There is a general belief that teachers with diploma qualifications add more value to the quality of educational provision in the country.

To improve access in education and ensure that children receive quality education the Revised National Policy on Education recommended that primary school teacher's qualifications be raised to diploma level.The Revised National Policy on Education also recommended that a package of incentives be created for teachers so that their morale and motivation is raised. It is stated in the Republic of Botswana, (1994, p.11) that "Government intends to embark on a number of measures aimed at raising the status and morale of teachers so that they can perform their tasks more effectively. Such measures will include both improved pre-service and inservice training, a package of incentives and improvements in the conditions of service". Furthermore, the RNPE of 1994 stated that "The quality of instruction is one of the most important determinants of the level of learning achievement. Teachers as agents of curriculum implementation are therefore central to the education system and can make or break the system. The enhancement of the status and motivation of teachers to enable them to discharge this role effectively cannot be over-emphasized"(Republic of Botswana, 1994, p.11.

The Revised National Policy on Education of 1994 recommended the reduction of class size. In the short term, class size in primary schools should be reduced to forty learners per class, while in the long-term the aim was to reduce the class sizes in primary schools to thirty learners per class (Republic of Botswana, 1994).

\section{THEORETICAL FRAMEWORK}

This study was informed by theConceptual Framework for Exploratory Study on Contributing Factors to Low Academic Achievement by (Nordin, Ahmad, Nayan, Yahya, Abdullah, Rahman, Ismail, and Yunus (2012, p. 107) shown in Figure 1 below. The framework was developed to examine factors contributing towards academic achievement within the three domains of personal efficacy and cognitive ability, support system and demographic factors. The domain of self-efficacy or personal efficacy and cognitive abilityinvestigates issues related to the learners' self efficacy, interest, basic learning skills, psychological factors and personality.It has 
been pointed out that the tenets of the self-efficacy component of social cognitive theory have been widely tested in various disciplines and settings and have received great support from a growing body of findings from diverse fields (Pajeres, 1996, p.1). In educational circles, studies by Lent, Larkin and Brown (1986, p.265) and Turner, Chandler and Heffer (2009, p.338) found that self-efficacy was a significant predictor of one's academic achievement. Educational studies have focused on exploring whether there is a link between efficacy beliefs and college major and career choices; secondly it has been suggested that the efficacy beliefs of teachers are related to their instructional practices and to various learners' outcomes; and thirdly, suggestions that learners' selfefficacy beliefs are correlated with other motivation constructs and with learners' academic performances and achievement. According to Feltz, Short, and Sullivan, (2008, p. 14), self-efficacy is: "an individual's belief or conviction that they can successfully achieve at a designated level on an academic task or attain a specific academic goal". It is the belief that one possesses the capabilities to organize, plan and carry out the courses of action required to manage situations at hand (Bandura, 1995).Abdallah, Fuseini, Abudu, and Nuhu (2014, p.1) emphasize this by pointing out that "for students to achieve high academic laurels, they need to believe that they can learn and that what they are learning is useful, relevant, and meaningful for them and for the society at large".

Figure 1: Conceptual Framework for Exploratory Study on Contributing Factors to Low Academic achievement.

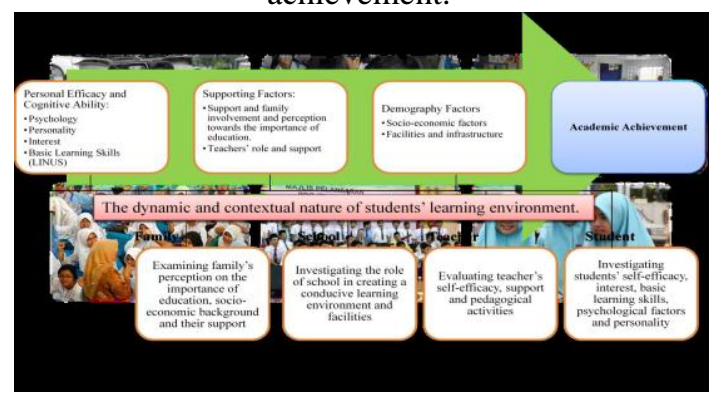

Thesecond domain of supporting factors examines issues of support and family involvement and their perceptions towards the importance of education. The third domain examines the socio-economic backgrounds of the parents and the support rendered. It also investigates the roles played by the school in creating a conducive learning environment and the facilities provided.Teacher's self-efficacy, support and their pedagogical activities are evaluated to determine their impact on students' performance. All these domains may lead to improved academic achievement.

\section{STATEMENT OF THE PROBLEM}

The Government of Botswana has invested in the development of the education system in its quest for quality education. Over the years the Government of Botswana came up with clear goals, comprehensive policies and aims with the hope that students' academic performance in the education system will improve. The academic performance of the students in the Primary School Leaving Examinations has been declining since 2004. Much as the Government has put much effort in the matter, it appears they are not sure of what factors really affect student academic performance in the education system. Therefore, the purpose of the study was to establish factors that influence student's performance in PSLE.

\section{RESEARCH QUESTIONS}

This study was guided by the following research questions:

1. What does academic performance mean?

2. What factors influence students' academic performance in Primary School Leaving Examination?

\section{METHODOLOGY}

In investigating factors that influence academic performance in primary school leaving examination in this study, a mixed research approach was used. Cresswell and Clack (2011) defined it as an approach in which both quantitative and qualitative approaches are used as they provide strengths that balance the waekness of both. Futhermore they were of the view that quantitative research makes it difficult for the researcher to understand the setting in which people talk and the voices of participants are not directly heard. Therefore qualitative research makes up for these weaknesses. Mixed methods research provided more evidence for studying a research problem than either qualitative or quantitative research alone (Cresswell \& Clack, 2011). The researcher decided to use mixed approach because it provided an opportunity for gathering detailed information as it used multiple tools for data collection. Using a questionnaire with both closed and open ended 
questions made the research more comprehensive(Johnson, Onwuegbuzie \&Turner, 2007).Fifteen respondents were interviewed as well.

\section{TARGET POPULATION AND JUSTIFICATION}

The study population consisted of Parent Teachers'Association (PTA) representatives, teachers and school management teams in Botswana primary schools. The researchers chose teachers because they are the key drivers of pupil's academic performance; therefore they are in a better position to judge the causes of pass or failure. School Management Teams also play a vital role of supporting implementation of development programs hence the need to include them in the target group. They are the accounting authorities in schools. School heads as instructional leaders play a vital role in directing program development and implementation (Republic of Botswana, 1994). The PTA representatives represent the voices of the communities in which schools are situated and therefore understand the issues that can influence students'academic performance.

\section{SAMPLE AND JUSTIFICATION}

A sample answers the question, who are the respondents in the study? A sample comprises of the individuals, items or events selected from a larger group referred to as a population (Gay, 2000). Similarly, Best and Kahn (2006) defined a sample as a small portion of the population that is selected for observation and analysis. The implication here is that a small portion of the population can be selected for observation and analysis, to represent the whole population. A sample is vital because it is cost effective in terms of time and money and it is the only option if accessing the population is impossible (Black, 1998).

Ten Bobirwa Inspectoral Area primary schools in the Central District of Botswana which were purposively selected were used. The sample for the quantitative aspect consisted of one hundred and seventy teachers, ten school heads, ten deputies and one PTA representative from each school (ten in all). These were randomly selected and the total number of respondents was two hundred which the researchers felt was adequate enough to answer the research questions. For the qualitative aspect, thirty respondents were purposively selected. These were respondents who possed rich information as identified for instance through formal interactions and the postions they occupied. For instance a PTA representative was included as the voice of the parents is necessary while school heads were included due to the instructional role they play in schools.

\section{INSTRUMEN}

Two instruments were developed and used in the study. Data for the quantitative aspect of the study was collected using a questionnaire with both closed and open-ended questions. The open-ended questions were meant to allow the respondents to freely express their opinions which the closed questions do not provide. The questionnaires also allowed for wide coverage of opinions. For the qualitative aspect, an interview schedule was developed by the researchers after extensive literature review in the area under study and analysis of of a few questionnaires and determining the the trends. The interview allowed for depth as the researchers could probe.The instruments were piloted in schools in the Gaborone Inspectoral Areato check whether there were sufficient options on multi choice answers and that there is sufficient discrimination inthe questions, so not all the answers are the same when there is likely to be a rangeof views/responses.The other reason for piloting wasto check for relevance, and whether the respondents understood what was required. Feedback from the piloting exercise was incorporated into the final instruments.

The researchers were equipped with request letters from the University of Botswana, which was used to introduce the researcher to the participants and show validity of the research. Each participant was assured all data collected was to be treated as confidential and used only for the purpose it was collected for. Particpants were not required to write their names anywhere on the questionnaire. They were also informed that participation was voluntary and they were free to terminate their participation at any stage of the study. The instruction on how to answer were clearly stated on the front page of the questionnaire for simplicity.

The questionnaires were distributed by the researchers to the participants. These questionnaires needed to be clearly monitored in order to achieve maximum participation. A total of thirty people were interviewed, five parents, five school heads, five deputies and fifteen teachers. The interviews were done by the researchers.Prior arrangements were made with those identified through the school heads'offices. Interviews lasted from fifteen to forty minutes depending on the respondents.

\section{DATA ANALYSIS}

Questionnaires were "cleaned"by the researchers as they arrived. This process of cleaning involved checking whether each questionnaire was properly completed and deciding whether to use the data or discard it. After this process the researchers coded the questions.For the closed ended questions in the questionnaire, SPSS (Statistical Package for the Social Sciences) was used.According to Obasi (2008) data processing and analysis is where a researcher represents the data collected with appropriate analytic tools already specified and adopted 
under the methodology. In analyzing data, the researchers used various techniques such as frequency tables, pie charts and bar charts. At the end of each technique, explanations were given for reference to interpret the exact representation of the facts on tabular format.Data was presented in percentages according to responses from respondents. This was done by grouping all opinions from respondents.

\section{X. $\quad$ FINDINGS AND DISCUSSIONS}

The findings of this study will be presented according to the research questions following the tenets of the conceptual framework presented in Figure 1 above.

\section{RETURN RATE}

Of the two hundred questionnaires distributed, one hundred and three questionnaires were returned. Three of the returned questionnaires were considered unusable as they were not filled properly and some were not complete. Therefore only one hundred were utilized as they were properly completed and contained meaningful data. One of the reasons for the average return rate was because these days teachers in the schools have developed negative attitudes towards researchers as they claim researchers waste their valuable time.

XII. THE CONCEPT OF ACADEMIC PERFORMANCE

In order to adequately answer the first research question, the researchers felt thatthere was a need to establish whether both parties understood the concept of academic performance the same way. Research question one sought to establish the concept of academic performance under the following headings: academic performance as the outcome of education; as measured by examinations; andas an indicator of the standard of education.

\section{Academic performance as the outcome of education}

This section presents and discusses the respondents' understanding of academic performance as the outcome of education.

Table 1: The outcome of education

\begin{tabular}{|l|l|l|}
\hline Item & Agree & Percent \\
\hline $\begin{array}{l}\text { Academic performance as the outcome } \\
\text { of education. }\end{array}$ & 99 & $99 \%$ \\
\hline
\end{tabular}

Table 1 shows that ninety nine (99\%) of the respondents understood academic performance as the outcome of

education. From the interviews, one teacher respondent defined academic performance as:

theway in which a learner, teacher or an institution have achieved their educational goals. It is usually measured by the way the teachers and the learners in a school perform and progress to the next level. It is reflected in the transition rates from a lower grade to a higher one. A school that is able to have more students progressing is judged to be performing well academically and in most cases parents prefer to send their children there.

From the open ended section of the questionnaire, another teacher respondent believes that academic performance is:

The ability of the learner to study hard and remember, and being able to communicate ones' knowledge orally orin written form. It also manifests itself in the results achieved based on intellectual ability of the learner. Mostly it is judged by the learner's pass mark.

A seniorteacher rinterviewedconcurs that academic performance means:

The overall display of what the learner has learnt and captured. It isthe rate at which the learner's progress in their learning field such as the results they obtain after sitting for a test or an exam, thus the level of education that can be attained and improved.Literature shows that measuring academic performance can occur at multiple levels and serve multiple purposes; for instance teachers in the classroomsconduct formative and summative tests to evaluate student mastery of coursecontent and provide grades for students and parents. Ganai and Mir (2013, p. 5) posit that:Academic achievement may be defined as excellence in all academic disciplines, in class as well as co-curricular activities. It includes excellence in sporting behaviour, confidence, communication skills, punctuality, arts, culture and the like which can be achieved only when an individual is well adjusted.

This is in line with what Trow (1956) cited in Ganai and Mir (2013, p. 5) defined academic achievement as "knowledge attaining ability or degree of competence in school tasks usually measured by standardized tests and expressed in a grade or units based on pupils' performance". Good (1959) also cited in Ganai and Mir (2013, p. 5) referred to academic achievement as, "The knowledge obtained or skills developed in the school subjects usually designed by test scores or marks assigned by the teacher". According to EbenuwaOkoh (2010, p.99)academic performanceis: 
defined or regarded as participants' examination grades (Grade point average) at the end of a particular semester or programme. It could also be seen as the level of performance in a particular field of study.

These sentiments are shared by Uwezo (2010) who declares that it is always good to track academic performance because it satisfies a number of purposes like areas of accomplishment and failure in a learner's academic work which needs to be evaluated in order to foster improvement and make full use of the learning process.

\section{Academic performance as measured by examinations}

Tan (2013, p.121) explained that "in educational institutions, success is measured by academicperformance, or how well a student meets standards set out bylocal government and the institution itself". This section presents and discusses the respondents' understanding of academic performance as measured by examination and continuous assessment.

Table 2: Measures of academic performance

\begin{tabular}{|l|l|l|l|}
\hline $\begin{array}{l}\text { Examination and continuous } \\
\text { assessment as measures of } \\
\text { academic performance }\end{array}$ & $100(100 \%)$ & Disagree & Total \\
\hline
\end{tabular}

Table 2 shows that $100(100 \%)$ of the respondents understood academic performance as measured by

Examinations and continuous assessment. In this study, academic performance was understood to mean, grades obtained in tests, in course work and in examination. A deputy headteacher interviewed clarified that:Examinations have been found to be the most adequate way to measure students' academic performance. One reason why they are thought to be adequate is because when students know that they are going to write an examination they prepare hard for that and try to do better. They make enough time and do extensive research. Therefore examinations can be regarded as adequate as a measure of students' academic performance.

A teacher respondent in the open ended section of the questionnaire explained that:

The overall achievements/results of the whole school based on the theoretical education that makes up the syllabus. It is based on examinations, tests, class exercises and quizzes. It is influenced by the nature of the school and how it is managed; that is the leadership styles applied by those in management. It is also influenced by teachers, parents and learners' behaviour. Another headteacher intervieweddescribed it thus:

It is how a centre of learning performs or achieves based on subject categories available. School performance can either be good or poor with regards academics. It is measured by pass rates at different grades or levels and periods. Schools have monthly tests and term examinations which are meant to assess the progress of students in their learning. There are also assessments such as quizzes and class-work which assess the progress of students on a daily basis per subject. All these reflect the academic performance of the school However the most used type of assessment of academic performance is the terminal examination which comes at the end of level, for example primary education.Yet another senior teacher expressed almost similar sentiments that:

Academic performance in schools is done after teaching and learning has taken place then the teacher evaluates whether learners have acquired what they learnt in a number of ways. For regular grading, students demonstrate their knowledge by taking written and oral tests, carrying out presentations, doing homework and participating in class activities and discussions. Teachers evaluate in the form of letter or number grades and remarks, to describe how well a student has done.

The above sentiments are also emphasized in the literature by Siddiek (2012, p.144) when he declares that: By means of examinations, we can be sure about the qualityof teaching done in the classroom by teachers. We can also be sure about the quality of the learning output judgedby students' performance in their achievement examinations. Examinations are tools of measurement of the degreeof the attainment of the national educational, social, political and religious objectives (agendas) of the nation orthe government. Ministries/Departments of education are the arms which the government let free to supervise theeducational objectives of the country and make them attainable.

Siddiek, (2012, p.136) further pointed out that:

National examinations are a means by which learners' academic achievements can be judged, through national competitions of standardized examinations. The examination is an effective tool for the assessment of educational objectives; as from the results achieved by students in these examinations, we can measure: the degree of their performance, to see the points of strength to reinforce them or to spot weaknesses tocure them. These tests can also tell us about the effectiveness of the teaching force in their practice in classrooms,as well as telling us about the success of the teaching units (curriculum). 
Although examinations should be a fair and just criterion to provide equal opportunities to all candidates, it should also be the means with which to measure the students' performances as well as to assess the teachingmethods (Siddiek, 2012). Adeyemi, (2005)sees academic achievementas a scholastic standing of a student at a given moment. That is, the ability of an individual todemonstrate his or her intellectual abilities. The RNPE of 1994 recommended that "...a more systematic approach in terms of data collection, statistical analysis etc should be adopted".

\section{FACTORS THAT INFLUENCE ACADEMIC PERFORMANCE}

The empirical findings reveal that there are many factors that influence the academic performance of schools and learners. This section discusses those factors identified by the respondents asinfluencingthe academic performance of learners in the Primary School Leaving Examinations in Botswana. The analysis and discussions are guided by the three domains of the conceptual framework for this study which are also aligned to the research questions guiding the study. The first domain deals with self-efficacy and cognitive ability, while the second focuses on supporting factors and the third deals with demographic factors.

\section{XIV. $\quad$ SELF-EFFICACY AND COGNITIVE ABILITY.}

The quality of education has been found to be directly related to the quality of teaching and learning (Caprara, Barbaranelli, Steca \& Malone, 2006). There are many factors that determine the quality of teaching, and these include among others teacher qualification and experiences (Caprara, Barbaranelli, Steca \& Malone, 2006). Therefore, it can be concluded that the recruitment of qualified teachers is one of the factors that influence students' academic performance. Kristonis, Herrington and Salinas (2006) assert that the growing interest in teacher quality is not a new theme in the educational arena as there is increased pressure for school accountability.

In this section an evaluation of teachers' self efficacy, support and pedagogical activities as well as investigating students' self efficacy, interest, basic learning skills, psychological factors and personality is done.Tschannen-Moran and Woolfolk-Hoy (2001) have defined teacher efficacy as: a teacher's judgment of his or her capabilities to bring about desired outcomes of student engagement and learning, even among those students who may be difficult or unmotivated" (p. 783). Over the years, several factors have been identified as predictors of academic performance and one of them is teacher self-efficacy, which includes variables such as interest, attitude, qualification and experience. From the findings of this study, it is apparent that the participants were well qualified and experienced as illustrated in Table 3 below.

Table 3: Qualifications, Experience and Age of respondents

\begin{tabular}{|l|l|l|l|l|l|}
\hline Qualifications & $\begin{array}{l}\text { No. of } \\
\text { respondents }\end{array}$ & Experience & $\begin{array}{l}\text { No. of } \\
\text { respondents }\end{array}$ & Age range & $\begin{array}{l}\text { No. } \\
\text { respondents. }\end{array}$ \\
\hline PTC & 8 & 0-10 years & 20 & $20-30$ years & 28 \\
\hline DPE & 79 & 6-10 years & 28 & $31-40$ years & 26 \\
\hline B.Ed & 13 & 11-15 years & 19 & 41-50 years & 27 \\
\hline & & $\begin{array}{l}\text { Above } 15 \\
\text { years }\end{array}$ & 33 & 51+ years & 19 \\
\hline
\end{tabular}

Table 3 shows that all the one hundred respondents in this study had the relevant qualifications required for

Primary School teachers in Botswana.It is emphasized in the RNPE that the Government of Botswana recognizes that:The quality of instruction is one of the most important determinants of the level of learning achievement. Teachers as agents of curriculum implementation are therefore central to the education system and can make or break the system. The enhancement of the status and motivation of teachers to enable them to discharge this role effectively cannot be overemphasized (Republic of Botswana, 1994, p.11).

As a result the Government embarked on a number of measures aimed at achieving the requirements of the recommendation and these included the qualifications of teachers, entry requirements as well as the duration of training. The minimum professional qualification of a primary school teacher is a Primary Teachers' Certificate (PTC) whose minimum entry requirements are five years of secondary education. The course duration is three years in the colleges of education. However, the Revised National Policy on Education of 1994 phased out the certificate and replaced it with a Diploma in Primary Education (DPE) hence the large numbers of teachers under this category. In the last ten years the Government of Botswana took a decision to upgrade all primary school teachers to degree level and the process is ongoing. The findings in this section also show a good mix of experienced and novice teachers. It has been argued in the literature that teacher qualifications that are considered to be related to studentlearning have become desirable targets of teacher education reform. Some of these reformscall for the professionalization of teacher education by making it longer, upgrading it tograduate 
programs, and regulating it through mechanisms of licensure, certification, andpromotion aligned with standards (Darling-Hammond, 1999; Darling-Hammond, Chung, \& Frelow, 2002). The Government of Botswana has followed this line as seen in the recommendations of the current education policy and the upgrading of all primary school teachers to degree level. It has further been pointed out by Yala and Wanjohi(2011) and Adeyemi (2010) that teachers' experience and educational qualifications were theprime predictors of students' academic achievement.Teachers' age may also be of importance for effectiveness but this variable is highly correlated with experience. On the whole, it appearsRockoff, Jacob, Kane, \& Staiger (2008) arguments that combined variables on teachers' cognitive and non-cognitive attributes are related to student achievement and their conclusions that "... there may be no single factor that can predict success in teaching, using a broad set of measures can help schools improve the quality of their teachers (p. 1)" may be true. Itcan therefore beconcluded thatfuture research should aim at addressing the gaps in knowledge about which teacher attributes and aspects of instruction have the greatest effect on student learning.

\section{SUPPORTING FACTORS}

The second domain of the conceptual framework that guides this study deals with factors that support the academic performance of students.As illustrated above this component of the conceptual framework focuses on two factors namely parental involvement and the role of teachers.

\section{PARENTAL INVOLVEMENT AND LEARNERS' ACADEMIC PERFORMANCE}

One of the most powerful but neglected factors that supportstudents' learning and development is parental or family involvement both in and out of school. For many years, researchers have been accumulating evidence to demonstrate that parental involvement is one of the strongestpredictors of learners' school success, and that families play pivotal roles in their children'scognitive, social, and emotional development frombirth through adolescence.

Table 4: Parental Involvement

\begin{tabular}{|l|l|l|l|}
\hline & Agree & Disagree & Total \\
\hline $\begin{array}{l}\text { Parental involvement accelerate } \\
\text { learning }\end{array}$ & $99(99 \%)$ & $1(1 \%)$ & $100(100 \%)$ \\
\hline
\end{tabular}

In Table 4 above, it is succinctly clear that ninety nine (99\%) of the respondents are of the view that the involvement of parents in their children's education can accelerate the learners' learning. From the semi structured interview, one deputy headteacher pointed out that: The parents in our school relate very with the teachers even though they are not that educated and most of the time they help their children with their homework, they try their best to help them with everything the school needs. Parents are always very supportive of teachers' initiatives to improve learners' academic performance by encouraging their children to come to school prepared. Therefore both teachers and parents are always there making decisions together that why we are always performing well in PSLE.A headteacher in the open ended section of the questionnaire declared that: As a school we encourage parental involvement in the education of learners by holding parents' meetings regularly and communicating with them well in time through their children. We also urge the learners to encourage their parents to attend meetings. Communication is the hallmark of successful parental involvement. Schunk and Pajares(2001) believe that parents' academic socialisation is the way in which parents influence students' academic performance by shaping students' skills, behaviours and attitudes towards school. Furthermore, academic socialisation can be influenced by parents' socio-economic status as highly educated parents tend to have a more stimulating learning environment (Meece, 1997). In most cases, parents'provide a warm, responsive and supportive home environment which in turn encourages exploration and stimulate curiosity, provide play and learning materials which accelerate children's intellectual development' (Meece, 1997).

It has been pointed out that when schoolwork involves parents, students learn more (Meece, 1997). Schools are encouraged to build strong alliances with parents and welcome their active participation in the classroom (Bandura, Barbaranelli, Caprara and Pastorelli, 1996) if they are to succeed in improving the academic performance of the learners. Educators are encouraged to inform parents of the school's educational goals, the importance of high expectations for each child, and ways of assisting with homework and classroom lessons (Bandura,1997).

Literature search on parental involvement highlights several factors that can influence parents'involvement in their children's education (Henderson \& Mapp, 2002).However, if they are not adequately addressed, they may present themselves as barriers to achieving parent involvement. The factors that are "barriers range from logisticalissues associated with parents getting out to school events to factors associated

DOI: $10.9790 / 0837-2109054053 \quad$ www.iosrjournals.org $\quad 47 \mid$ Page


with the schoolculture and how welcoming the school is to parents' (Mitchell, 2008, p.2).For instance, in the current study a class teacher interviewed felt that some of the challenges faced by schools include:

Parental involvement in our school is a challenge due to the fact that most parents work far away from their children as a result children are left with their grandparents who are failing to help the children with their school work because the syllabus content is way beyond their understanding and this weakens our PSLE results.

Yet another class teacher from the open ended section of the questionnaire declared:

There is no cooperation between the PTA and the teachers and as a result the teacherstake decisions on their own because when the PTA is called for meetings they don't come.As class teachers we try by all means to meet with individual parents but only a few come and the rest don't show interest. Some learners are very bright and could be performing very well but just because their parents have negative attitudes their performance always drops tediously.

Studies on parental involvement have indicated that parents with higher levels of education are more likely to be involved in their children's schools (Tinkler, 2002).Students with parents who are involved in their school tend to have fewer behavioral problemsand better academic performance, and are more likely to complete high school than studentswhose parents are not involved in their school(Hendersonand Berla, 1994). Positive effects of parental involvement havebeen demonstrated at both the elementary and secondary levels across several studies, withthe largest effects often occurring at the elementary level. The current study shows that primary schools in Botswana are trying very hard to involve parents in the education of their children but they are met with various challenges. They are also guided by the RNPE of 1994 which stated that p.52: "The Government should intensify the efforts to encourage the establishment of PTAs".

\section{School Learning Environment and academic performance}

Apart from the home environment described above, another very critical factor influencing academic performance is the school learning environment. According to the UNESCO Institute for Statistics (2012, p. 12), learning environment refers to:

the complete physical, social and pedagogical context in whichlearning is intended to occur. The term most often refers to school classrooms but may includeany designated place of learning such as science laboratories, distance learning contexts,libraries, tutoring centres, teachers' lounges, gymnasiums and non-formal learning spaces.The components and attributes of a learning environment are conceptualized in relation totheir impact on learning processes and outcomes in both cognitive and affective domains. This term may also refer to the natural environment surrounding school buildings when theyare used as a learning space.

Literature search has described school learning environment as encompassing those factors within the school that may or may not provide suitable conditions for the promotion of effective teaching and learning; and these include teacher qualification, teacher availability, class size, availability of teaching and learning materials, monitoring, contact hours, school ownership (i.e., private or public), motivation of teachers, and teachers absenteeism/commitment to duty (Abdalla., Fussein., Abudu., \& Nuhu, 2014; Win \& Miller, 2004). This study has revealed that teachers in Botswana primary schools are well educated and experienced. Respondents were further asked to rate the impact of the learning environment on academic performance.

Table 5: Impact of learning environment on academic performance

\begin{tabular}{|l|l|l|}
\hline $\begin{array}{l}\text { Learning environment as having } \\
\text { impact on learners academic } \\
\text { performance. }\end{array}$ & $88(88 \%)$ & $12(12 \%)$ \\
\hline
\end{tabular}

Table 5 shows that $88 \%$ of the respondents were of the opinion that the learning environment had great impact on the academic performance of the learners in the PSLE results. Those interviewed had the following to say concerning the different components of the Learning environment.

\section{Infrastructure}

The Government of Botswana recognized the crucial role played by infrastructure in providing quality education as illustrated in the National Development 8 where it is stated that: "Facilities of primary schools will be improved by adding libraries, providing electricity, adding more classrooms to ensure reduced class sizes from 40 to 30 and procurement and distribution of school supplies will be improved" (Republic of Botswana, 1997, p.359). With respect to primary school facilities and standards, the RNPE of 1994 stipulated that a standard school should have the following as a minimum (p.15):

\section{Physical Facilities}

- Adequate number of classrooms up to a maximum of 22 
- Administration block with office space for the headteacher, deputy headteacher and typists, staffroom and 2 storerooms for storage of books and food

- Library

- Resource centre

- Fully equipped Science room/Science Equipment

- Room for health activities

- A sports field for various sporting activities

- A tool shed for storage of agricultural and other tools

- Teachers' quarters with a minimum of 2 bedrooms

- Adequate toilet facilities (including provision for the disabled)

- Sufficient land for agricultural purposes and future development, and

- Electrification of school buildings including teachers' quarters.

On the issue of the state of the school infrastructure, a headteacher interviewed declared that:

Poor infrastructure has been a major challenge which caused academic failure but the government has done its best by renovating old buildings and even building new ones. In the olden days teaching used to take place under trees but this is a thing of the past as all students are taught in well-established classroom and this is one of the best developments which have improved the schools today. Also we have the administration block which has offices and a big staffroom where teachers work comfortably. Teachers' houses are also up to standard.

A parent interviewed supported the above assertion by pointing out that:

Government schools in Botswana are the same in terms of facilities they offer, the buildings in them are the same the teachers' houses are the same, they write the same examination, and they go for vacation at the same time and students are taught the same subjects and content all over the country.

Ayeni and Adelabu (2012, p.62) emphasized the importance of the school learning infrastructure by pointing out that the quality of learning the facilities available within an educational institution such as a school has a positive relationship with the quality of teaching and learning activities which in turn lead to improved academic performance. They further highlight that the quality of the school buildings and furniture can also have an impact in the performance of students in their final year.

\section{EDUCATIONAL RESOURCES AND ACADEMIC ACHIEVEMENT}

Research shows that there is a relationship between the availability of quality educational resources in schools and academic performance. Savasci and Tomul (2013, p.114) have argued that "...the effects of educational resources on student achievement depends on the development of a country as well".

Table 6: The impact of resource on academic performance

\begin{tabular}{|l|c|c|c|}
\hline $\begin{array}{l}\text { Enough teaching and learning } \\
\text { materials } \\
\text { achievement }\end{array}$ & $100(100 \%)$ & - & $100(100 \%)$ \\
\hline
\end{tabular}

Table 6 shows that all (hundred per cent) of the respondents agreed that by providing schools with enough

Teaching and learning materials will improve. From the open ended section of the questionnaire a headteacher had this to say:Schools are given adequate teaching and learning materials like stationery and books but the problem is that in our school management likes keeping these resources in the storeroom (for security reasons) without allocating them for classes to utilise. This makes teachers to struggle as they improvise most of the time while materials are rotting in the storerooms.

This study has also illustrated that while schools were provided with enough teaching and learning materials, there were instances of mismanagement of resources in schools as allocation is not done effectively. From the open ended section of the questionnaire a classteacher pointed out that:We used to have plenty of materials in the olden days but nowadays when you talk about materials all they say at the Regional Offices is that companies which are supposed to supply delayed or they talk about issues of tight budgets. Sometimes schools take the whole term without preparation books and students are told to buy their own booksand most don't buy as they claim that they do not have money for that. Whether they write or not it is the teacher's problem.Thisstudy has revealed that there are a lot of challenges when it comes to the procurement of educational resources which hindered the teachers from effectively carrying out their duty properly.For instance if at the beginning of the term there are no preparation books teachers start the term at a very low morale wiseworrying about the fate of learners who had no exercise books to write on and this has an undesirable influence on the academic performance. These sentiments shared by Yara and Otieno (2010). One respondent in this study had this to say:The syllabus has changed drastically; it is complex and demanding, but as teachers we 
are only provided with shallow text books whichare full of contradictions to use as reference materials. Schools are not provided with social media like internet so that teachers and learners can make further research on certain topics they do not understand. The situation is sometimes compounded by the Government taking decisions without first ascertaining the availability or otherwise of educational resources in the schools. Teaching and learning materials need to always be available to foster understanding (Adekomi, 1998) It has also been stressed that a good instructional material supplements spoken or written word and it can bring teaching to life more than the word can. A head teacher interviewed echoed this by saying that:

The Ministry of Education and Skills Development prematurely implemented the new syllabus without assessing its demands. For example, the syllabus objectives of Science, Agriculture and Creative and Performing Arts (CAPA) call for a lot of practical work and experiments to be done but there are no labs or even the apparatus to do these experiments. Pupils are taught the theory because of lack of the required materials which cannot be substituted for, consequently learners fail at a high rate than before the new syllabus was implemented. These confirm the assertion that there is a relationship between academic performance and educational resources. On top of the physical facilities stipulated in the RNPE of 1994, the policy lists the following as the standard minimum for primary schools (Republic of Botswana, 1994, p.16):

\section{Equipment/Supplies}

- Typewriter/computer (Headteachers have been provided with laptops since 2014)

- Reprographic equipment (cyclostyling machine/photocopier)

- Telephone where available(Headteachers have been provided with cellphones since 2014)

- Library books

Support staff

- School secretary (to be shared where practicable)

The policy further recommends that: "PTAs should be encouraged to add to this minimum, for example in the provision of computers and library books, in order to enrich the curriculum of the school". The inclusion of such recommendations in the policy demonstrate the commitment of the Botswana Government to enhance the academic performance of all learners at primary school irrespective of locality. This was to achieve issues of access and equity as required by the World Conference on Education for All in Jomtien, Thailand (5-9 March 1990) to make primary education accessible to all children and to massively reduce illiteracy before the end of the decade.

\section{English as a medium of communication}

Like most former British colonies, Botswana adopted English as the official language and language of instruction from the early stages of the education system and this has come with its challenges. For instance deputy headteacher from the open ended section of the questionnaire had this to say:

From standard two all subjects are taught in English in exclusion of Setswana to pupils who never attended preschool therefore is hard for them to comprehend and respond to anything which is communicated to them in English. There is nothing we can do about this, since we have too many objectives to cover in a short period and a lot of unexpected activities throughout the year which affect the class calendar. So our plans as teachers to integrate activities which can help pupils to practice and gain knowledge in English Language are always failing due to lack of time.A class teacher added by declaring that:Most standard seven learners are struggling to communicate in English and that could be one of the factors that put them at a disadvantage, since that is the language used to respond to questions in the examination. Hoang $(2008$, p.32) identified the same challenges and and posited:

Learning English is not relevant to learners' purposes. Theycan't understand a lecture in English. They can't communicatein English (in daily or professional situations). They can't readtheir professional or common sense reading materials texts. They can't write in English. Therefore, although theirmotivation to learn English is high, they achieve very little.Nevertheless, English is still a subject at higher education institutions.

One parent interviewed felt that:

I think if our children were taught in Setswana they could be performing much better their major problem is that they do not understand English because when I help my child with her schoolwork she will fail to respond to questions but when I ask her in Setswana she responds well, which means she understood English she could have been performing better.

In Botswana, the RNPE of 1994 emphasized that with respect to the teaching of languages in primary school:

a) English should be used as the medium of instruction from Standard 2 as soon as practicable.

This recommendation was based on the realization that there is poor performance of primary school children in English and part of the problem is that children do not get used to using English early enough in the learning process and yet they are required to write their examinations in the language. Using English as the medium of instruction from Standard 2 will improve their performance (Republic of Botswana, 1994, p.60). 
The medium of instruction plays a crucial role in teaching and learning process as it is significant in the academic outcomes of the students (Flowerdew, 1994). It is the language through which teachers and students communicate with each other during the teaching and learning process. The medium of instruction is of vital importance in schools because through it learners understand what is being taught. (Flowerdew, 1994). Another major driving force behind this English-medium instruction policy is a common belief that teaching subject courses in English can promote students' interest and motivation in learning the English language, and hence improve their proficiency, while at the same time facilitating their academic performance and increasing their knowledge (Dupuy, 2000).

\section{Libraries in schools}

Libraries are an important but poorly developed feature of infrastructure in Botswana primary schools. This was emphasized by head teacher in the open ended section of the questionnaire who declared that:

Although the education system in Botswana has certainly improved, one of the major issues which is still lagging behind is the lack of libraries in primary schools. For teachers to instil the culture of reading among learners there has to be a foundation laid from an early age so that learners can get used to visiting the library and be able to research on their own and realise that if they made a research on a certain topic, they became competent in it and consequently easy for them to pass.

A class teacher pondered that:

Poor academic performance is caused by not having libraries especially in remote areas where one finds that if you don't understand something and try to ask other co-workers they also don't understand. One ultimately gives up because there is nothing one can do about it since there is no where you can go to find that information. It would be a good idea if schools in the remote areas can have libraries because we can spend time studying and preparing better content for learners also learners can develop some good reading and research skills, this will also kill boredom since we have nothing to do at all.

Libraries are important in helping academics generate information for the purpose of effective teaching of students and research (Ubegu, 2006). Baffour-Awuah (2002, p.26) posits that in Botswana, the 'responsibility for school libraries has been shared by two ministries, a situation that is still hurting Botswana's school library development. The Ministry of Education is responsible for providing library structures, stock, and equipment in educational institutions, and the National Library Service is responsible for staffing educational libraries. The National Library Service helps schools to start school libraries, lends books on request, holds training courses for teacher-librarians and students assistants, and provides bibliographies and catalogues to assist teachers in book selection'.

Morris (2004) asserts that, school libraries are distinct from public libraries because they serve as "learner-oriented laboratories which support, extend and individualise the school's curriculum....A school curriculum serves as the center for coordinating agency for all materials used in the school" (32).Advocates of school library media programs have long been convinced of the relationship between quality library media programs and academic achievement (Lance, 1993). This is supported by Lansdale (2003) who says that researchers have demonstrated that school libraries have a positive impact on students' achievement. In terms of student achievement, in every grade, students who score better in reading tests were likely to do better on their use of language and use of the library media center, (Roser \& Forest, 1990). For this reason, reading scores alone are highly used to represent academic achievement, (Roser and Forest, 1990).

\section{CONCLUSIONS AND RECOMMENDATIONS}

It can therefore be concluded that despite the many challenges faced by developing countries, the Government of Botswana has invested a lot of resources in education. The Government has consistently allocated over 20\% of its budget to education even before the Conference on Education for All of 1990, thanks to the revenues from the diamonds and prudent expenditures adopted by the powers that be. The Government has also created a conducive environment by developing policy guidelines, developing infrastructure and training teachers. However, in spite of these achievements, the academic performance is not as impressive as it is supposed to be with the commitment shown. It can be argued that much as there is commitment on paper, there are subtle challenges that bedevil the education system, thus affecting the academic performance of learners. For instance the recommendations of the two policies on education have not been fully implemented. The Government has followed what can be termed a mathematical approach where quantitative means have taken precedence. For instance, more learners are in schools despite the shortage of classroom space in some schools; the learner-teacher ratio has not been taken cognizance of so that the Government can boast of meeting the $100 \%$ enrolment in primary schools. Most of the primary school teachers' certifications have been upgraded to Diploma and degree level without taking cognizance of the quality factors. These teachers are taught in most cases but mediocre qualified lecturers who themselves have gone through the same programme. When upgrading the qualifications of the teachers to Diploma and Degree level, very little or nothing was done to cater 
for the deficit in content as most of those who took primary teaching went as far as Junior Certificate and needed more content. This deficit also applied to those who trained teachers in the colleges of education and the Department of Primary Education at the University of Botswana.

Despite having more learners of diverse abilities in the classrooms, there is very little evidence that teachers are able to adjust their teaching strategies to the audience. There is very little professional development for these teachers as those who are supposed to offer such interventions are found wanting.

\section{REFERENCES}

[1] Abdallah, H., Fuseini, M. N., Abudu, A. M. and Nuhu, Y. (2014).Dilemma of Basic School Pupilsin Northern Ghana with respect to Their Learning Context,Education Research International. Vol. 2014. Pp 1-13.

[2] Adeyemi, B. (2010). Teacher Related Factors as Correlates of Pupils Achievement in Social Studies in South West Nigeria. Electronic journal of Research in Educational psychology, 8(1): 313-332.

[3] Adeyemi, T. O.(2005). Predicting students' performance in senior secondary certificate examinations from performance in the junior secondary certificate examinations in Ondo state, Nigeria. Multidisciplinary Journal of Research Development. 6(3):74-85.

[4] Ayeni, A. J. and Adelabu, M. A. (2012).Improving learning infrastructure and environment for sustainable quality assurance practice in secondary schools in Ondo State, South-West, Nigeria International Journal of Research Studies in Education. 1 (1), 61-68.

[5] Bandura, A. (1995).Self-efficacy in Changing Societies, Cambridge: Cambridge University Press, 1995.

[6] Feltz, D., Short, S., and Sullivan, P., 2008. Self-efficacy in sport-research and strategies for working with athletes, teams, and coaches. United States: Human Kenetics.

[7] Baffour - Awuah, M. (2002). School libraries in Botswana: A state of the art report . Gaborone: Botswana National Library Services. Educational Libraries Division.

[8] Bandura, A. (1997). Self-efficacy: The exercise of control. New York: Freeman.

[9] Bandura, A., Barbaranelli, C., Caparara, G. V., and Pastaroli, C. (1996). Multifacted impact of selfefficacy beliefs on academic functioning. Child Development, 67(3): 1206-1222.

[10] Best, J.W. and Kahn J.V. 2006 Research in education. United state of America: Pearson.

[11] Black, S. (1998). Money and the Art of Staff Development. Journal of Staff Development, 19(4): 14-17.

[12] Caprara, G. V., Barbaranelli, C., Steca, P., and Malone, P. S. (2006). Teachers' self-efficacy beliefs as determinants of job satisfaction and students' academic achievement: A study at the school level. Journal of School Psychology, 44, 473-490.

[13] Creswell J. W, and Clark V. L. (2011). Designing and Conducting Mixed Methods Research. 2nd

[14] ed. Los Angeles: Sage Publications.

[15] Darling-Hammond, L., Chung, R., and Frelow, F. (2002). Variation in teacher preparation: How well do different pathways prepare teachers to teach? Journal of TeacherEducation, 53 (4), 286-302.

[16] Darling-Hammond, L. (1999). Teacher quality and student achievement. Washington: Centre for the Study of Teaching and Policy, University of Washington.

[17] Darling-Hammond, L. (2000). Teachers' Quality and Students' Achievement. A Review of State Policy Evidence, 8(1).

[18] Dupuy, B. C. (2000). Content-based instructions: Can it help ease the transition from beginning to advance foreign classes? Foreign Language ANNALS, 33(2), 205-223.

[19] Ebenuwa-Okoh, E. E. (2010). Influence of Age, Financial Status, and Gender on Academic Performance among Undergraduates. Journal of Psychology, 1 (2): 99-103

[20] Flowerdew, J. (1994). Academic listening: Research perpective. Cambridge: Cambridge University Press.

[21] Ganai, M. Y. and Mir, M. A. (2013). A comparative study of adjustment and academic achievement of college students. Journal of Educational Research and Essays, 1(1), pp. 5- 8.

[22] Henderson, A. T.\&Mapp, K. L. (2002), A New Wave of Evidence:

[23] The Impact of School, Family and Community Connections on Student Achievement, Southwest Educational Development Laboratory. Austin.

[24] Henderson, A. T., and Berla, N. (1994). A new generation of evidence: The family is critical to

[25] student achievement. Washington, DC: National Committee for Citizens in Education.

[26] Hoang, V. V. (2008). Factors affecting the quality of English education at the Vietnam National.

[27] University, Hanoi. Journal of Science, Foreign Language.24: 22-37.

[28] Johnson, R.B., Onwuegbuzie, A., \& Turner, L. (2007). Toward a definition of mixed methods

[29] research . Journal of Mixed Methods Research, 1(2), 122-133.

[30] Lance, K.C., Welborn, L., and Hamilton-Pennell, C. (1993). The Impact of School Library Media Centers on Academic Achievement, Hi Willow Research and Publishing, Castle Rock, Colorado. 
[31] Lansdale, M. (2003). Impact OF school libraries on student achievement: A review of the research. Retrieved from http://www.asla.org.au/research/research.pdf

[32] Meece, J. L. (1997). Child and adolescent development fo educators. New York: McGraw-Hill.

[33] Ministry of Education, (2010). Botswana lower primary syllabus. Retrieved from . http://www/index.php?id=171

[34] Mitchell, C. A. (2008). Parent Involvement in Public Education: A Literature Review. Philadelphia: Research For Action.

[35] Mmereki, O. A. (2011). Quality of Primary School Inputs in Botswana. Gaborone: Ministry of Education.

[36] Monyaku, B. and Mmereki, O. A. (2012). Availability and distribution of resources in Botswana primary schools and their relationship with pupils' learning achievements.

[37] Morris, B. (2004). Administering the school library media centre. Westport: Libraries Unlimited. (p.32).

[38] Nordin, S., Ahmad, W. F. W., Nayan, M. Y., Yahya, N., and Abdullah, A. (2012). A Conceptual Framework in Examining the Contributing Factors to Low Academic Achievement: Self-Efficacy, Cognitive Ability, Support System and Socio-Economic. Paper presented at the International Conference on Management, Social Sciences and Humanities in 2012.

[39] Republic of Botswana. (1977). Education for Kagisano. Gaborone: Government Printers.

[40] Republic of Botswana. (1994). Revised National Policy on Education. Gaborone: Government Printers.

[41] Rockoff, J. E., Jacob, B. A., Kane, T. J., \& Staiger, D. O. (2008). Can you recognize an effective teacher when you recruit one? (NBER Working Paper No. 14485). Cambridge, MA: National Bureau of Economic Research. Retrieved from http://www.nber.org/papers/w14485

[42] Roser, N. L., Hoffman, J.V.,and Farest, C. (1990). Language literature and at-risk children. The Reading Teacher, 43(8),554-559.

[43] Siddiek, A. G. (2012). The General Certificate Examinations as a Tool of Measurement \& Quality Control of Educational Objectives in Some Arab Countries with Special Reference to Saudi Arabia, in American International Journal of Contemporary Research. 2(5):138-148).

[44] Savasci, H. S. and Tomul, E. (2013). The Relationship between Educational Resources of School and Academic Achievement, International Education Studies, 6(4): 114-123.

Shunk, D. \&. (2001). Development of acchievement motivation.

[45] Tan, R. D. (2013). Psychometric Examination Results and Academic Performance of Irregular Students in a University, Cebu City Philippines. 2nd International Conference on Management, Humanity and Economics (ICMHE'2013) May 6-7, 2013 Kuala Lumpur (Malaysia)

[46] Tinkler, B. (2002). A review of literature on Hispanic/Latino parent involvement in K-12 education. Retrieved from ERIC database (D469134). Retrieved 16/01/2015 from: http://www.eric.ed.gov/PDFS/ED469134.pdf

[47] Tschannen-Moran, M. \& Woolfolk-Hoy, A. (2001). Teacher efficacy: capturing an elusive construct. Teaching and Teacher Education, 17, 783-805.

[48] Turner, E.A., Chandler, M., Heffer, R.W. (2009). The Influence of Parenting Styles, Achievement Motivation, and Self-Efficacy on Academic Performance in College Students. Journal of College Student Development, 50(3): 337-346.

[49] UNESCO Institute for Statistics (2012). A PLACE TO LEARN:Lessons from Research on Learning

[50] Environments. Succursale Centre-Ville Montreal: Quebec.

[51] University of Botswana. (2010). An Evaluation of the Substance of the Prmary Schools. Gaborone.

[52] University., Y. (1998). Sampling; Social Research Methods: Procedures in Sampling. Yale Statistics Department of Statistics.

[53] Uwezo. (2010). Are our children learning: Annual Learning Assessment Report . Dar es salaam: Uwezo TENMET \& Hivos/Twaweza.

[54] Win, R and Miller, P. W. (2004). The effects of individual and school factors on university students' academic performance. CLMR Discussion Paper Series 04/4, The Centre for Labour Market Research, The University of Western Australia, 2004.

[55] Yala, P. O. \& Wanjohi, W. C. (2011). Performance Determinants of KCSE in Mathematics in Secondary Schools in Nyamira Division, Kenya. Asian Social Science, 7(20): 107-112.

[56] Yara, P. O. Otieno, K. O. (2010). Teaching/Learning Resources and Academic Performance in Mathematics Secondary Schools in Bondo District of Kenya. Asian Social Science (ASS), 6(12):126-132. 